\title{
A Rapid Screening Method for the Detection of Benzodiazepine Drugs in EnvironmentalSamples By MALDI-TOF Mass Spectrometry
}

\author{
Nunes,C. N.;* Komatsu, E.; Perreault, H.; Quináia, S. P. \\ Rev. Virtual Quim., 2020, 12 (1), 248-260. Data de publicação na Web: 2 de março de 2020
}

http://rvq.sbq.org.br

\section{Um Rápido Método de Triagem para a Detecção de Drogas Benzodiazepínicas em Amostras Ambientais Empregando Espectrometria De Massa Maldi-Tof}

Resumo: Benzodiazepínicos (BDZs) são considerados contaminantes de preocupação emergente e têm sido frequentemente encontrados em ambientes aquáticos. Devido à possível ecotoxicidade destes compostos, se faz necessário avaliar sua presença e distribuição no ambiente aquático. O presente trabalho traz uma introdução ao MALDI-TOF para a determinação qualitativa rápida de benzodiazepínicos em amostras de água e sedimentos. A extração dos BDZs da água foi feita pelo métdo QuEChERS (quick easy cheap effective rugged and safe) e uma extração sólido-líquida foi usada para amostras de sedimentos. Um procedimento de limpeza (cleanup) adaptado com ponteiras de $200 \mu \mathrm{L}$ e cinco camadas de discos de extração sólida (EmporeTM 2215 - C18 C18 (octadecyl) 47 mm (3M, London, On)) e a extração sólido-líquida foram eficientes e picos com adequada relação sinal-ruído foram obtidos para o alprazolam (ALP) e diazepam (DIAZ) em amostras enriquecidas. O método não foi sensível para o clonazepam (CLO). Os limites de deteç̧ão para o DIAZ e ALP em água de rio foram de 2,5 e 5,0 $\mu \mathrm{g} / \mathrm{L}$ respectivamente. Nas amostras de sedimentos, os limites de detecção alcançados foram de $40 \mathrm{ng} / \mathrm{g}$ para ambas as drogas.

Palavras-chave: Análises ambientais; contaminantes de preocupação emergente; fármacos; sedimentos.

\begin{abstract}
Benzodiazepines drugs (BDZs) are considered as contaminants of emerging concern (CECs) and have often been found in aquatic environments due to the possible ecotocicity of these compounds, it is necessary to evaluate their presence and distribution in the aquatic environment. The present work introduces a MALDI-TOF-MS methodology for the quick and qualitative detection of BDZs in water and sediment samples. The extraction of BDZs from water was done by the "quick easy cheap effective rugged and safe method (QuEChERS), and solid-liquid extraction was used for the sediment samples. The cleanup procedures employed homemade stage tips prepared with five layers of Empore ${ }^{\mathrm{TM}}$ SPE disks 2215 - C18 (octadecyl) $47 \mathrm{~mm}$ (3M, London, On) inside $200 \mu \mathrm{L}$ Eppendorf ${ }^{\mathrm{TM}}$ tips. QuEChERS and solid-liquid extraction were effective, and peaks with adequate signal-to-noise ratio were obtained for alprazolam (ALP) and diazepam (DIAZ) in spiked samples. The method was not sensitive to clonazepam (CLO). Limits of detection (LODs) for DIAZ and ALP in river water were 2.5 and $5.0 \mu \mathrm{g} / \mathrm{L}$, respectively. In sediment samples, LODs achieved were $40 \mathrm{ng} / \mathrm{g}$ for both drugs.
\end{abstract}

Keywords: Contaminants of emerging concern; environmental analysis; pharmaceutical compounds; sediments.

* Universidade Estadual do Centro-Oeste, Departamento de Química, Campus CEDETEG, Rua Simeão Varela de Sá, CEP 85040-080, Guarapuava-PR, Brasil.

chaldernunes@gmail.com DOI: $\underline{10.21577 / 1984-6835.20200019}$ 


\section{A Rapid Screening Method for the Detection of Benzodiazepine Drugs in Environmental Samples By MALDI-TOF Mass Spectrometry}

\section{Chalder Nogueira Nunes, ${ }^{\mathrm{a} E m y ~ K o m a t s u,}{ }^{\mathrm{b}}$ Hélène Perreault, ${ }^{\mathrm{b}}$ Sueli Pércio Quináia}

a Universidade Estadual do Centro-Oeste, CEP 85040-080, Guarapuava-PR, Brazil. ${ }^{b}$ University of Manitoba, R3T 2N2, Winnipeg-MB, Canada.

*chaldernunes@gmail.com

\section{Recebido em 11 de outubro de 2018. Aceito para publicação em 10 de dezembro de 2019}

\section{Introduction}

\section{Experimental}

2.1. Reagents and solutions

2.2. Mass spectrometry

2.3. Sampling sites and sample preparation

\section{Results}

4. Conclusion

\section{Introduction}

There have been reports of pharmaceutical compounds detected in aquatic environments. ${ }^{1-3}$ Mendoza et al (2014) have found drugs of abuse and benzodiazepines in a river in the region of Madrid. ${ }^{1}$ In the same region, Valcárcel et al (2011) evaluated the presence of 33 pharmaceutical compounds in river and tap water. Twenty-five pharmaceutical compounds and metabolites were detected downstream in the outlet of sewage treatment plants (STPs) and five substances were detected in tap water. ${ }^{2}$ In addition, Matongo et al (2015) studied the presence of caffeine, antipyretics, antibiotics, antiepileptic and antipsychotic drugs in wastewater, water and sediments. Some drugs were detected in all matrices. ${ }^{3}$ Low efficiency of STPs and direct input of raw sewage are the main causes of environmental contamination by pharmaceutical compounds. It has been reported that several STPs do not remove the totality of drug contaminants from effluents. ${ }^{4-7}$ The presence of these contaminants of emerging concern (CECS) in river and lake aquatic environments threatens to cause attain more general contamination of aquatic bodies, along with associated ecotoxicological risks. ${ }^{8}$ When drugs are transported to aquatic environments, they may remain in the water column or be deposited within sediments, depending on their physicochemical characteristics. A few studies have investigated these behaviors. For instance, da Silva et al. (2011) have shown that most drugs stay in the water column, while others with high pKa values (basic) are mainly bound to suspended solids.

Benzodiazepines (BDZs) are psychotropic drugs used in the treatment of insomnia, anxiety, panic disorders, seizures and other brain disorders. They are also used as muscle relaxants. BDZs were among the most prescribed psychotropic drugs around the world. ${ }^{9}$ The presence of BDZs in the environment has been reported in different countries. ${ }^{10-14}$ Recent studies on fish reported that low concentrations of BDZs in their fresh 
water living environment could lead to a range of problems. ${ }^{15-17}$ Brodin et al (2013b) studied the influence of oxazepam on perch fish and their prey damselfly larvae. The authors reported behavior changes in the fish, as they became more aggressive. Changes in feeding rate were noticed, however, the damselfly behavior was not affected. In addition, the authors suggested a bioaccumulation of the drugs, resulting in the fish being exposed to high levels of drugs throughout the food chain. ${ }^{15}$ Other benzodiazepines such as clonazepam, bromazepam and diazepam are also known to have caused behavior changes in fish. Gebauer et al. (2011) noticed a reduction of shoal cohesion in zebrafish after they were exposed to these drugs for 10 minutes. ${ }^{17}$ Overturf et al. (2016) exposed catfish to $1.0 \mu \mathrm{g} \mathrm{L}^{-1}$ of diazepam for 7 days. They noticed no behavior change in the fish, but bioaccumulation and endocrine disruption effects were observed. All these observations suggest that problems caused by BDZs in aquatic systems may induce environmental imbalances and behavioral changes that may alter the population of some species.

Thus, it is necessary to establish a survey of data on the presence of these contaminants in the environment. In this sense, effective and rapid methodologies must be developed for the screening of these drugs in samples of environmental concern. Methods for the determination of drugs in environmental samples commonly use chromatography, and most use liquid chromatography (LC)..$^{18}$ Although, it is true that modern liquid chromatographic techniques such as UPLC-MS systems, which employ short length and small inner diameter column, allow to reduce operational costs and solvent consumption per analysis, these chromatographic systems are highly expensive. In many laboratories, especially in developing countries, conventional chromatography is still in use. Conventional high performance liquid chromatography coupled with photodiode array detection (HPLC-DAD) consumes high amounts of organic solvent and are not environmentally friendly. In this view, fast, effective and environmental friendly methods are preferable.

Matrix assisted laser desorption/ionization time-of-flight mass spectrometry (MALDI-TOFMS) is a great screening tool for the detection of organic compounds. MALDI involves soft ionization of the analytes by a laser beam. Ionization is supported by a matrix, i.e. a weak organic aromatic acid able to absorb the laser energy and promote ionization of the target compounds. Different matrices can be used for this purpose, for instance, sinapinic acid (SA), 2,5-dihydroxybenzoic acid (DHB), a-cyano-4-hydroxy cinnamic acid (CHCA), ${ }^{19-21}$ 2,5-dihydroxybenzoic acid and 2-hydroxy-5-methoxybenzoic acid (SDHB), $2^{\prime}, 4^{\prime}, 6^{\prime}$-trihydroxyacetophenone monohydrate (THAP). ${ }^{22}$ However, it is important to emphasize that MALDI has some difficulties with regard to matrix compounds and determination of small molecules. These target compounds have $\mathrm{m} / \mathrm{z}$ values in the range of common matrix compounds, these characteristics may make it difficult to differentiate between analytes and background. In contrast, MALDI-TOF-MS offers many advantages such as short analysis time, low sample amount requirements, simultaneous determination of various analytes, and possibility of performing tandem MS depending on the instrument model used. MALDI is an environmentally friendly technique as it does not require large volumes of organic solvents or toxic reagents. It is also a very rapid technique: In the method presented here, extractions can be completed in 2 hours as for MALDI, less than five minutes are needed to prepare the equipment for analysis. Preparation includes docking the target, pumping down the sample chamber area, and focusing the laser source. The sample target can hold more than 300 samples. Each sample is analyzed in three minutes or less by several laser shots. The total analysis time is then short, considering that a large mass range is observed in each measurement. LC and gas chromatography (GC) methods require on average ten minutes for benzodiazepines analysis. ${ }^{13,23}$ Setting up GC and LC equipment can be longer: changing, cleaning and conditioning columns, modifying mobile phases and attaining proper working pressure can be lengthy procedures. Also, in GC and HPLC, after each injection it is necessary to wait until all compounds are eluted. Overall, MALDI-TOFMS analysis times are much shorter than LC or GC times.

MALDI-TOF-MS has been used in many fields of study such as proteomics, glycomics, and mycotoxin studies. ${ }^{19,24-26}$ Only a few research groups studied small molecules (e.g pharmaceutical compounds) using this technique. Nozawa et al. (2016) developed a MALDI-TOF- 
MS method for the determination of six tricyclic antidepressants and related drugs in urine and blood. Their method was used for real samples and the LODs were as low as $0.3-2 \mathrm{ng} / \mathrm{mL} .{ }^{27}$ Nozawa et al. (2015) developed a rapid and sensitive method for the determination of eight BDZs and two metabolites in blood using MALDI-TOF-MS. Alphacyano-4-hydroxy cinnamic acid was used as a matrix to provide $\mathrm{BDZ}$ ionization. The method was optimized and applied successfully for forensic purposes. ${ }^{21}$ So far, no MALDI-TOF-MS method has been proposed for BDZ screening in environmental samples. Natural water and sediment analysis requires significant pretreatment steps due to the complexity of environmental matrices. Indeed, environmental samples contain many potential interferences due to the presence of organic compounds (natural and contaminants) and inorganic species. ${ }^{28-31}$ Organic analytes can interact with the organic matter and particulate materials present in water and sediment samples, making matrices even more complex..$^{32}$ These interactions can be significant and extraction processes are mandatory, otherwise drugs they are not released and thus unavailable for analysis. Each sample is unique, with particular characteristics. Different $\mathrm{pH}$ values and physicochemical parameters make extractions and determinations challenging. The optimization of the extraction process is essential even if mass spectrometric "universal" detection is to be used. Although biological samples such as blood and urine contain several potential interferences, they are much more similar to each other than environmental matrices, which can differ on a wide physicochemical range.

In the present work, a MALDI-TOF-MS methodology was optimized for the detection of two benzodiazepines drugs, alprazolam (ALP) and diazepam (DIAZ), in fresh water and sediments. The detection of another BDZ, clonazepam (CLO), was also studied, although no concluding results were obtained for this drug. Two extraction methods were developed, and a cleanup procedure was necessary to remove interferences from sediment samples. The three BDZs considered were among the most sold psychotropic drugs in the world. ${ }^{23}$ They are very inexpensive and popular drugs. 16,33,34 ALP and DIAZ are mostly used to treat anxiety, panic disorders and alcohol withdrawal symptoms. CLO if often used to treat certain types of seizures, and for panic disorders. ${ }^{16,33,35}$ Figure 1 shows the chemical structures of BDZs studied in the present work.

MALDI-TOF-MS was chosen as the main detection technique in the present work, for the afore-mentionned reasons, mostly speed of analysis, low environmental waste and ability to detect several molecules simultaneously on a large mass range. The main objective of the present paper is to present methodology developed for the screening of BDZs in environmental samples using extraction and MALDI-TOF-MS.

\section{Experimental}

\subsection{Reagents and solutions}

Methanol, acetone and acetonitrile (all LCMS grade), as well as acetic acid were purchased from EMD Chem (Germany), sodium chloride and magnesium sulfate were from Fisher Scientific (Canada), and ultrapure water $(0.055 \mu \mathrm{S} / \mathrm{cm})$ was purified on aSimplicityIV Milli-Q system (Millipore). ALP and DIAZ were purchased from Pharmanostra (Brazil), while CLO was purchased from Fagron (Brazil). Standard stock solutions of BDZs were prepared by dissolving the proper amount of drug in $10 \mathrm{~mL}$ of acetonitrile and refrigerating. Work solutions were prepared by dilutions of the stock

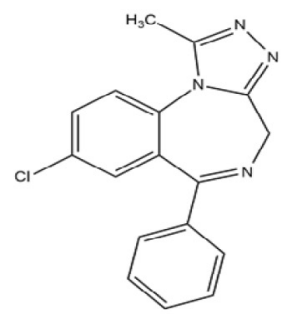

alprazolam

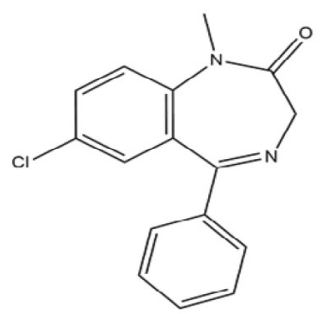

diazepam

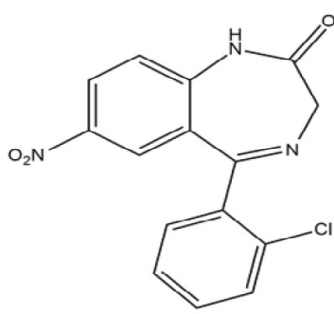

clonazepam

Figure 1. Chemical structures of ALP, DIAZ and CLO 
solutions in $1 \mathrm{~mL}$ of water. Sinapinic acid (SA, Sigma Aldrich, Canada), 2,5-dihydroxybenzoic acid (DHB, Sigma, Oakville, Canada), 2,5-dihydroxybenzoic acid plus 2-hydroxy-5-methoxybenzoic acid (SDHB, Sigma), 2',4',6'-trihydroxyacetophenone monohydrate (THAP, Fluka, Canada) and $\alpha$-cyano4-hydroxy cinnamic acid (CHCA, Aldrich, Canada) were evaluated as matrices for the optimization of BDZ ionization efficiency. Reproductive surface coverage and good signal-to-noise levels were taken into account for the choice of the matrix. Besides ionization efficiency for BDZ, each matrix tested had unique characteristics of surface coverage and fragmentation patterns.

\subsection{Mass Spectrometry}

MALDI-TOF-MS measurements were carried out on an UltraFleXtreme ${ }^{\text {TM }}$ MALDI-TOF/TOF mass spectrometer (Bruker Daltonics, Leipzig, Germany) equipped with LID-LIFT ${ }^{\mathrm{TM}}$ technology for tandem MS experiments, and with a Smartbeam laser $(1000 \mathrm{~Hz}$ ). Laser shots (from 1000 to 7000 ) were used to acquire spectra. The laser power used was adjusted between 29 and 40\%, and spectra were acquired in reflector positive ion mode within a mass range of $0-500 \mathrm{~m} / \mathrm{z}$. The ion source 1 and 2 voltages were set at $20 \mathrm{kV}$ and $17.8 \mathrm{kV}$, respectively. The lens voltage used was 7 $\mathrm{kV}$, the pulse ion extraction time was $140 \mathrm{~ns}$, and the detector voltage was optimized at $2.4 \mathrm{kV}$. A volume of $1 \mu \mathrm{L}$ of solution containing the sample and the matrix, in a ratio of 1:1, was deposited on the target. The specific method conditions were developed by the authors.

\subsection{Sampling sites and sample preparation}

Fresh water and sediment samples were collected and kept in glass bottles until the start of the extraction procedure. Water samples were stored at $-4^{\circ} \mathrm{C}$. Sediments were dried at room temperature $\left(22^{\circ} \mathrm{C}\right)$, macerated and sieved to remove twigs and small stones. The samples analyzed in this work were from Canada and Brazil. Brazilian sediment samples were collected in a spring affluent of the Iguaçu reservoir $\left(25^{\circ} 23^{\prime} 38.14^{\prime \prime}-51^{\circ} 29^{\prime} 8.10^{\prime \prime}\right)$ and downstream of a sewage treatment plant waste in Guarapuava city - Parana state $\left(25^{\circ} 24^{\prime} 50.26^{\prime \prime}-51^{\circ} 30^{\prime} 54.84^{\prime \prime}\right)$, around $450 \mathrm{~m}$ below the effluent input. Canadian samples of water and sediments were collected in rivers within urban perimeters and in a lake in a national park. Samples sites were in Winnipeg MB (Red River (49 $\left.81^{\prime} 29.80^{\prime \prime}-97^{\circ} 13^{\prime} 06.75^{\prime \prime}\right)$ and Seine River (49 $\left.\left.83^{\prime} 49.40^{\prime \prime}-97^{\circ} 08^{\prime} 66.54^{\prime \prime}\right)\right)$, Magog

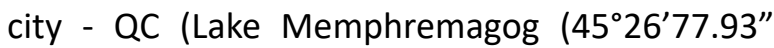
- $\left.72^{\circ} 16^{\prime} 07.19^{\prime \prime}\right)$ ), Montreal - QC (Prairies River $\left(45^{\circ} 53^{\prime} 90.00^{\prime \prime}\right.$ - 73 $\left.\left.71^{\prime} 27.39^{\prime \prime}\right)\right)$ and Whiteshell Park - MB (Brerenton Lake $\left(49^{\circ} 91^{\prime} 14.89^{\prime \prime}\right.$ $\left.95^{\circ} 52^{\prime} 61.32^{\prime \prime}\right)$ ).

Freshwater samples collected were extracted by the QuEChERS (Quick Easy Cheap Effective Rugged and Safe) method adapted from Westland and Dorman. ${ }^{36}$ This liquid-liquid extraction method consists of separating target compounds from the aqueous solution with an organic solvent in the presence of salts. For this purpose, $0.5 \mathrm{~mL}$ of sample was mixed with the same volume of acetonitrile. The mixture was vortexed for $1 \mathrm{~min}$. Then, $0.2 \mathrm{~g}$ of $\mathrm{MgSO}_{4}$ and $0.05 \mathrm{~g}$ of $\mathrm{NaCl}$ were added and the mixture was vortexed again. The solution was centrifuged and the supernatant was collected, evaporated under a gentle air flow and the residue was reconstituted in $10 \mu \mathrm{L}$ of acetonitrile/water (7:3).

For sediments, optimization of the extraction and cleanup procedures was necessary. Analyses without a cleanup procedure were not possible due to prominent sample matrix effects. The development of an effective cleanup step was then essential. Extraction and cleanup studies were performed using $0.1 \mathrm{~g}$ of sample weighed in a $1.5 \mathrm{~mL}$ microcentrifuge tube and spiked with $0.5 \mu \mathrm{g} \mathrm{g}^{-1}$ of each drug. The extraction was carried out with $2 \times 1 \mathrm{~mL}$ of methanol and $2 \times 1 \mathrm{~mL}$ of acetone, in a scheme modified from the method by Ternes et al. ${ }^{37}$ The organic extracts were pooled and evaporated under a gentle air flow. The residue was reconstituted in $200 \mu \mathrm{L}$ of $2 \%$ methanol in water. Then, the extract was passed through a homemade stage tip micro column (stop-and-go-extraction tip, prepared with 5 layers of Empore SPE disk 2215 - C18 (octadecyl) $47 \mathrm{~mm}(3 \mathrm{M})$ inside a $200 \mu \mathrm{L}$ Eppendorf tip) ${ }^{38}$ previously conditioned with $100 \mu \mathrm{L}$ of methanol and equilibrated with $100 \mu \mathrm{L}$ of water. The sample was loaded on the tip, and after interaction with the $\mathrm{C} 18$ phase, washed with the cleanup solutions to eliminate impurities. The eluting solvents, used in the cleanup and elution processes, consisted of water (A) and methanol (B), both modified with $0.1 \%$ of acetic acid. As BDZs are soluble in 
methanol and slightly soluble in water (DIAZ 50 $\mathrm{mg} \mathrm{L}^{-1}$, ALP $32 \mathrm{mg} \mathrm{L}^{-1}$ and CLO $100 \mathrm{mg} \mathrm{L}^{-1}$ at $25^{\circ} \mathrm{C}$ ), different proportions of the $A / B$ blend $(9: 1$, $7: 3,6: 4$ and 4:6) were evaluated for cleanup, prioritizing that analytes would not elute during the initial cleanup, but sequentially afterwards in the eluate in progressive $A / B$ proportions. While 9:1 and 7:3 A/B solutions were primarily aqueous and used for cleanup, either $6: 4$ or $4: 6$ was used to collect the extracts of interest.

\section{Results}

Solutions containing $1 \mathrm{mg} / \mathrm{L}$ of each BDZ were used to optimize some instrumental parameters. lon source voltages, detector and lens voltages as well as pulse ion extraction time and laser power were evaluated to find the best analytical signal. This evaluation resulted in the following optimized parameters: ion source voltages 1 and 2, $20 \mathrm{kV}$ and $17.8 \mathrm{kV}$, respectively; detector voltage $2.4 \mathrm{kV}$, lens voltage $7 \mathrm{kV}$, and pulse ion extraction time $140 \mathrm{~ns}$. The laser power was adjusted between 29 and $40 \%$.

In MALDI analysis, matrices are important to promote the ionization of analytes. Usually, weak organic acids are employed for this purpose. Important interferences from the matrix are observed in the low mass range, making it difficult to study low molecular weight compounds. Some authors used surfactants in order to suppress the matrix related background. ${ }^{39}$ In the present work, the use of different matrices was evaluated, aiming to find the best conditions for the simultaneous detection of BDZs. In order tto characterize BDZ signals, each drug was analyzed individually after deposition of $0.5 \mu \mathrm{L}$ of a $1 \mathrm{mg} / \mathrm{L} \mathrm{BDZ}$ solution on the target with matrix. Figure 2 shows MALDI spectra of BDZs obtained with different matrices. It is noticeable that DHB, CHCA, THAP and SDHB matrices favored the ionization of DIAZ as $[(\mathrm{M}+\mathrm{H})]^{+}$ (Figure 2a). Good intensity signals were obtained for this drug with all matrices. In the case of ALP, the best signal intensity was achieved using DHB, however, it resulted in a wide peak. CHCA and THAP yielded good responses as well. In order to optimize conditions for the ionization of CLO, all matrices were tested, with only CHCA producing a good response. As the intent was to find conditions for the determination of all three BDZs together, CHCA was the best matrix and chosen for further experiments. Subsequent measurements were carried out with lower BDZ concentrations (10 $\mu \mathrm{g} / \mathrm{L})$, and MALDI $[\mathrm{M}+\mathrm{H}]^{+}$signals were observed only for CHCA. A thin and homogeneous layer obtained with this matrix allowed the detection of low concentrations of the drugs, justifying the choice of this matrix.

After selecting the best matrix among the five tried, the effect of CHCA concentration was studied. CHCA solutions of 2.0, 1.5, 1.0, $0.5 \mathrm{mg} /$ $\mathrm{mL}$ and a saturated solution were prepared and analyzed by MALDI in two steps, i) without BDZs and ii) spotted with $0.5 \mu \mathrm{L}$ of a solution containing $100 \mu \mathrm{g} / \mathrm{L}$ of BDZs. To summarize, it was noticed that high matrix concentration promoted better signals, hence a saturated solution was chosen as it provided the best BDZ signals (data not shown).

BDZ extraction studies for environmental water samples by QuEChERS were performed in drug-spiked $(10 \mu \mathrm{g} / \mathrm{L})$ and non spiked samples. These extracts were analysed in detail. Figure 3 shows the spectra obtained from the Red River water extracts. In Figure 3a, the spectrum was obtained with a non-enriched sample. Although some peaks are visible at $\mathrm{m} / \mathrm{z} 288.15,294.08$, 303.34, etc.), no $[\mathrm{M}+\mathrm{H}]^{+}$peaks referring to DIAZ at $\mathrm{m} / \mathrm{z} 285.08$, ALP at $\mathrm{m} / \mathrm{z} 309.09$ and CLO at $\mathrm{m} / \mathrm{z}$ 316.04 are present, evidencing the absence of these BDZs from this sample. Figure $3 b$ shows the spectrum of a fresh water sample spiked with 10 $\mu \mathrm{g} / \mathrm{L}$ of each BDZ. Signals from DIAZ, ALP and CLO are visible and good intensity is observed for DIAZ and ALP. However, the signal referring to CLO is too low, without a good signal/noise ratio. Actually, studies performed with this BDZ (CLO), even with standard solutions, were inadequate due to the low sensibility of the method to this drug. This can be due to CLO having the lowest pKa (1.5, 2.4 and 3.5 for CLO, ALP and DIAZ respectively). For this reason, it is difficult to ionize this drug in the positive mode, in the presence of acid MALDI matrix. Experiments with CLO were thus not continued and for the remaining part of this work, only ALP and DIAZ were considered. Regarding the extraction procedure, QuEChERS was adequate for the elimination of interferences and for the extraction and pre-concentration of DIAZ and ALP drugs. Further experiments were then performed with this extraction method.

With the aim of extracting DIAZ and ALP from spiked and non-spiked sediments, methanol and acetone were used as extraction solvents. 

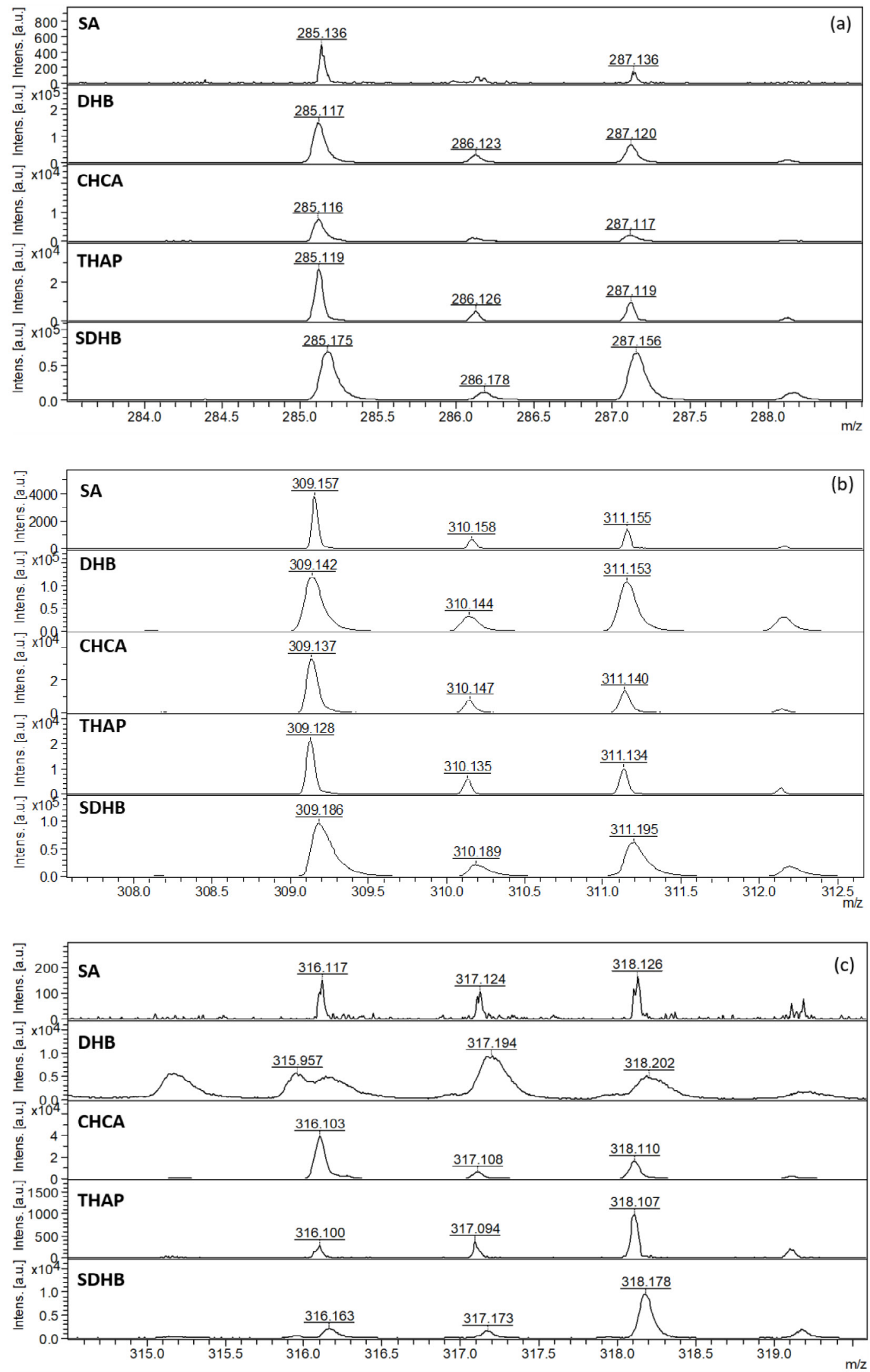

Figure 2. MALDI-TOF-MS spectra of BDZs obtained using different matrices (SA, DHB, CHCA, THAP, SDHB). Samples were $0.5 \mu \mathrm{L}$ of $1 \mathrm{mg} / \mathrm{L}$ solution of (a) DIAZ, (b) ALP and (c) CLO. Parameters used for these measurements: ion source 1, $20 \mathrm{kV}$ and 2, $17.8 \mathrm{kV}$; lens voltage, $7 \mathrm{kV}$; pulse ion extraction time, $140 \mathrm{~ns}$ and detector voltage, $2.4 \mathrm{kV}$ 


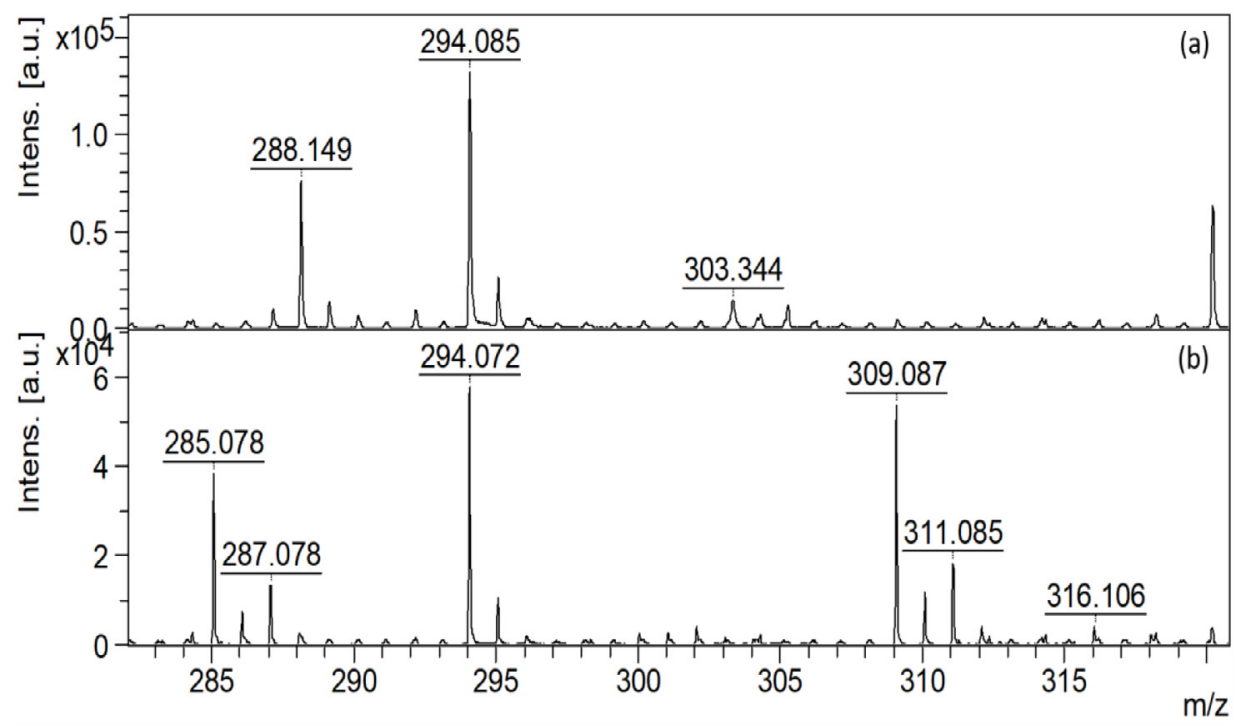

Figure 3. MALDI-TOF-MS spectra of (a) fresh water extract from the Red River and (b) fresh water extract from the Red River spiked with $10 \mu \mathrm{g} / \mathrm{L}$ of DIAZ, m/z $285.08[\mathrm{M}+\mathrm{H}]^{+}, \mathrm{ALP}, \mathrm{m} / \mathrm{z} 309.09[\mathrm{M}+\mathrm{H}]^{+}$ and CLO, $\mathrm{m} / \mathrm{z} 316.04[\mathrm{M}+\mathrm{H}]^{+}$

Although these drugs have high affinity for sediments (represented by log Kow, the n-octanolwater partition coefficient, which is 2.82 for DIAZ and 2.12 for ALP), they are quite soluble in organic solvents like methanol and acetone and thus can be extracted by using these solvents. ${ }^{32,37,40}$ Following this reasoning, two extractions of 1 $\mathrm{mL}$ of each solvent were carried out, totalizing $4 \mathrm{~mL}$ of organic solvent. The drugs were efficiently removed from sediments, however the determination of BDZ from these extracts was not possible due to sample matrix interferences. For this reason, a cleanup procedure needed to be developed. The complete extraction and cleanup procedures are described in Section 2.3.

The cleanup procedure was optimized to improve the analytical signal without analyte loss. As previously mentioned, DIAZ and ALP are quite soluble in methanol, however, they are practically insoluble in water. It was necessary to evaluate different ratios of methanol and water as a cleanup solution in samples enriched with DIAZ and ALP. In preliminary tests, the target compounds were eluted in $4: 6 \mathrm{~A} / \mathrm{B}(\mathrm{A}=0.1 \%$ of acetic acid in water, $B=0.1 \%$ of acetic acid in methanol). A large amount of interferences eluted with the target compounds, decreasing the signal of BDZs (figure not shown). Another sample was spiked and the cleanup conditions of $6: 4 \mathrm{~A} / \mathrm{B}$ were evaluated as well (Figure 4a), and it was noticed that the drugs started to elute under these conditions and kept eluting until $A / B$ was brought to $4: 6$ (Figure $4 b$ ). In Figure $4 c$, with elution using $100 \% B$, the absence of BDZ peaks instead of no $\mathrm{PBDZ}$ peaks indicated that all drugs were completely removed with the previous elution (A/B 4:6). Cleanup solutions must have proportions below $40 \%$ B to avoid BDZ removal. The elution can be performed with a $A / B$ 4:6 solution.

Lower proportions of cleanup solvent B component were tested to improve the cleanup procedure. Before the SPE elution of BDZs, the stage tip was washed once with $100 \mu \mathrm{L}$ of 9:1 $A / B$ and $7: 3 A / B$ to remove interfering salts and other compounds. This procedure was efficient to cleanup the samples without removing the analytes. Then, the stage tip was eluted with $100 \mu \mathrm{L}$ of $4: 6 \mathrm{~A} / \mathrm{B}$. This volume was evaporated under a gentle stream of air, and the sample was reconstituted with $10 \mu \mathrm{L}$ of 7:3 acetonitrile/water. The sample was then spotted onto the MALDI target $(0.5 \mu \mathrm{L})$ and analyzed. Figure 5 shows that this cleanup procedure was able to remove most interferences to produce good signals for DIAZ, $\mathrm{m} / \mathrm{z} 285.09[\mathrm{M}+\mathrm{H}]^{+}$and $\mathrm{ALP}, \mathrm{m} / \mathrm{z} 309.09[\mathrm{M}+\mathrm{H}]^{+}$.

After the optimization of the MALDI analytical protocol for BDZs and of the extraction procedures for BDZs in water and sediment samples, the limits of detection (LODs) were evaluated for both types of samples. LODs were determined by measuring the lowest detectable concentration. ${ }^{41}$ Solutions of $2.5,5.0$ and $10.0 \mu \mathrm{g} / \mathrm{L}$ were analysed. In these 


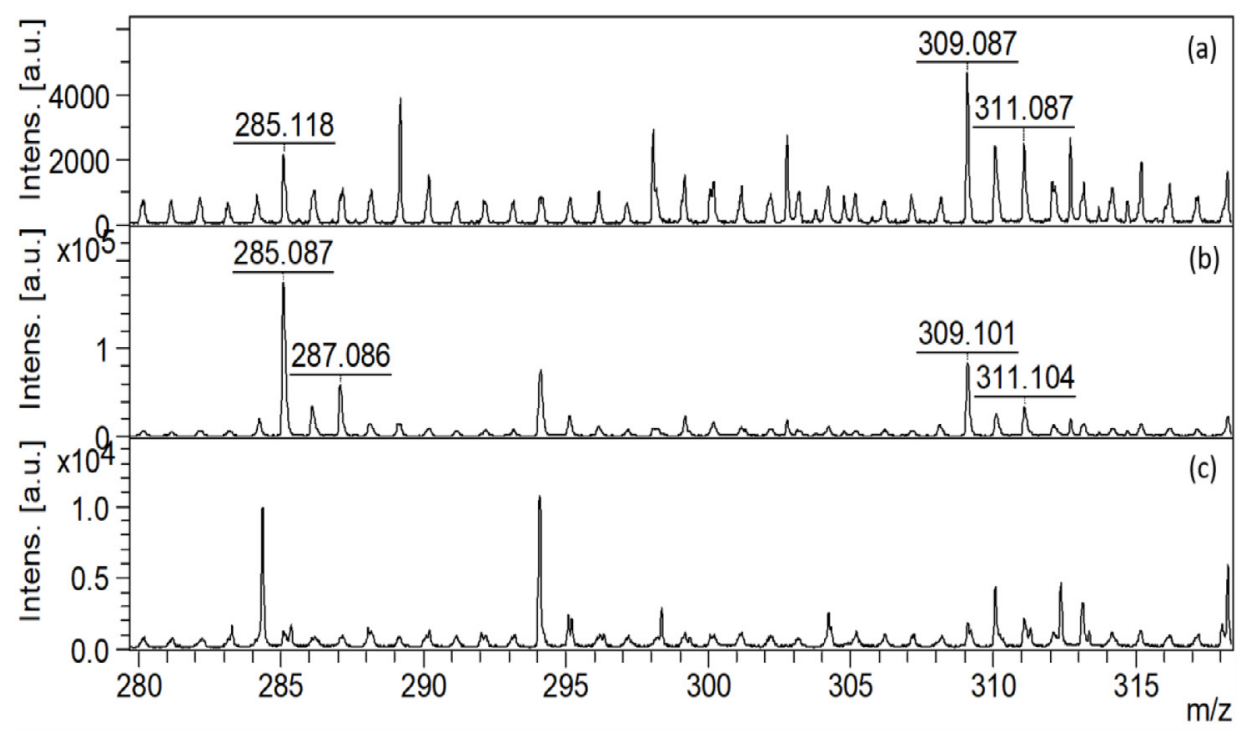

Figure 4. MALDI-TOF-MS spectra obtained from the optimization of the extraction and cleanup procedures for BDZs in a single enriched sediment sample. In this example, $0.5 \mu \mathrm{g} / \mathrm{g}$ of DIAZ and ALP were spiked in sediment samples from the Red River. a) Cleanup with 6:4 A/B; b) cleanup with 4:6 A/B;

c) $100 \%$ B. $A=0.1 \%$ of acetic acid in water, and $B=0.1 \%$ of acetic acid in methanol

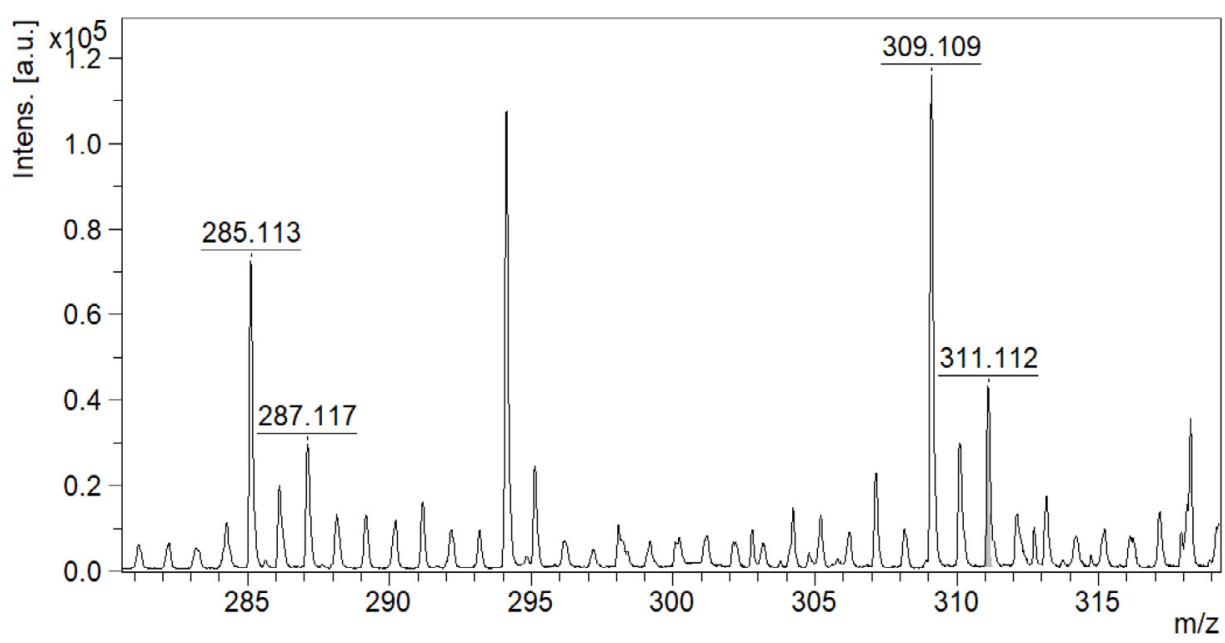

Figure 5. MALDI-TOF-MS spectrum obtained with optimized cleanup and extraction procedures for the detection of $0.5 \mu \mathrm{g} / \mathrm{g}$ of DIAZ and ALP spiked in a sediment sample from the Red River

experiments, $0.5 \mathrm{~mL}$ of natural water and $0.4 \mathrm{~g}$ of sediments, both from the Red River, were spiked with adequate amounts of DIAZ and ALP and then extracted. The LOD for DIAZ and ALP in fresh water were 2.5 and $5.0 \mu \mathrm{g} / \mathrm{L}$, respectively, and 40 $\mathrm{ng} / \mathrm{g}$ for both drugs in sediments.

The LODs obtained for DIAZ and ALP in water samples were relatively low and close to values previously presented in the literature. ${ }^{21}$ The comparison between the LODs obtained here and the values of Nozawa et al (2015) for BDZs in blood $(0,07$ to $2 \mathrm{ng} / \mathrm{mL})$ shows that LODs in fresh water were higher than in biological samples. It is important to take into account that environmental samples are very different from blood and high levels of interferences can be observed. Although some researchers have reported water drug concentrations close to LODs achieved in the present work, BDZs might be present at ultra trace levels, i.e. around ng/L.8,10,11 Da Silva tested the presence of 43 drugs in the Ebro river basin, Spain. Water analysis revealed 31 drugs in concentrations from $\mathrm{ng} / \mathrm{L}$ to $\mu \mathrm{g} / \mathrm{L}$. The LODs achieved here for water samples are high in some 
cases. As for the determination of drugs in fresh and waste water, SPE has been previously applied successfully to enrich samples. ${ }^{42,43}$ High volumes of water have typically been used as samples for SPE in extractions. For instance, Montagner and Jardim passed $1000 \mathrm{~mL}$ of surface water through a HLB OASIS 500-mg cartridge to pre-concentrate 15 CECs, i.e. a $2000 \times$ higher volume than the one used in this work. ${ }^{43}$ LODs found in the present work could be improved significantly by increasing the sample volume.

LODs achieved here for DIAZ and ALP in sediment were sufficiently low relative to values found in earlier studies. Indeed, other researchers reported sediment drug concentrations that were in the same range as reported in this work. $^{44-46} \mathrm{It}$ is also important to note that $0.4 \mathrm{~g}$ of sediment was used in the present work. The amount of sediment could be increased and consequently, better LODs could be achieved. Increasing the mass of sample would imply increasing extraction flask volumes. Presented as it is, our method uses $1.5 \mathrm{~mL}$ microcentrifuge extraction tubes, which are well portable and inexpensive. Larger sampling volumes would also involves larger cleanup solvent volumes, which move away from the green aspect of these experiments.

The newly developed extraction procedures were applied to water and sediment samples. Most samples were collected in urban areas in Canada. The analytes were below the LODs in all samples analyzed. The absence of these drugs in Canadian samples can be the result of good infrastructure for the collection of domestic and hospital sewage, together with adequate waste treatment. For Brazilian samples, BDZs were not found either. The first sediment sample was collected in a spring without contamination and was thus free of BDZs. The second sample was collected downstream of a STP, and was susceptible to being contaminated. As BDZs were not detected in this sample, probably the concentrations of the analytes were below the LOD of the method.

\section{Conclusion}

Although MALDI-TOF-MS has been mostly used to study macromolecules, this work shows the possibility of applying this technique to rapid and environmental friendly measurements of drugs of low molecular mass. As a highlight, this is the first study to report on the detection of BDZs, $D I A Z$, and ALP in environmental samples using MALDI-TOF-MS. The LODs achieved were not as low as those obtained with other techniques, ${ }^{14,23}$ however the sample volumes (water) and masses (sediment) used in this study were lower than those reported in the literature..$^{43}$ The use of larger amounts of sample as well as further improvements to the extraction/preconcentration procedures can potentially contribute to decrease LODs for BDZs in water and sediment in the future. The method was not sensitive to the CLO drug under the conditions used, i.e. the positive ionization mode with CHCA matrix. Further attempts to ionize CLO in the negative mode with a different matrix could also prove to be successful in future work. To summarize, the authors recommend MALDI-TOFMS for the detection of BDZs and other drugs in environmental samples as long as concentrations are above the LODs reported here.

\section{Acknowledgements}

This study was financed in part by the Coordenação de Aperfeiçoamento de Pessoal de Nível Superior - Brasil (CAPES) - Finance Code 001, Conselho Nacional de Desenvolvimento Científico e Tecnológico - Brasil (CNPq) and Fundação Araucária - Brasil (FA). The authors gratefully acknowledge financial support from CAPES through the PDSE program, NSERC (Natural Sciences and Engineering Research Council of Canada), University of Manitoba - UofM and Universidade Estadual do Centro-Oeste UNICENTRO.

\section{References}

${ }^{1}$ Mendoza, A.; Rodríguez-Gil, J. L.; González-Alonso, S.; Mastroianni, N.; López de Alda, M.; Barceló, D.; Valcárcel, Y. Drugs of Abuse and Benzodiazepines in the Madrid Region (Central Spain): Seasonal Variation in River Waters, Occurrence in Tap Water and Potential Environmental and Human Risk. Environment International 2014, 70, 76. [CrossRef] [PubMed] 
${ }^{2}$ Valcárcel, Y.; González Alonso, S.; RodríguezGil, J. L.; Gil, a.; Catalá, M. Detection of pharmaceutically active compounds in the rivers and tap water of the Madrid Region (Spain) and potential ecotoxicological risk. Chemosphere 2011, 84, 1336. [CrossRef] [PubMed]

${ }^{3}$ Matongo, S.; Birungi, G.; Moodley, B.; Ndungu, P. Pharmaceutical residues in water and sediment of Msunduzi River, KwaZulu-Natal, South Africa. Chemosphere 2015, 134, 133. [CrossRef] [PubMed] 4 Wilkinson, J. L.; Swinden, J.; Hooda, P. S.; Barker, J.; Barton, S. Markers of anthropogenic contamination: A validated method for quantification of pharmaceuticals, illicit drug metabolites, perfluorinated compounds, and plasticisers in sewage treatment effluent and rain runoff. Chemosphere 2016, 159, 638. [CrossRef] [PubMed]

${ }^{5}$ Manoli, K.; Morrison, L. M.; Sumarah, M. W.; Nakhla, G.; Ray, A. K.; Sharma, V. K. Pharmaceuticals and pesticides in secondary effluent wastewater: Identification and enhanced removal by acidactivated ferrate(VI). Water Research 2019, 148, 272. [CrossRef]

${ }^{6}$ Paíga, P.; Correia, M.; Fernandes, M. J.; Silva, A.; Carvalho, M.; Vieira, J.; Jorge, S.; Silva, J. G.; Freire, C.; Delerue-Matos, C. Assessment of 83 pharmaceuticals in WWTP influent and effluent samples by UHPLC-MS/MS: Hourly variation. Science of the Total Environment 2019, 648, 582. [CrossRef]

7 Tas, D. O.; Sari, S.; Aydın, E.; Topuz, E.; Pehlivanoğlu-Mantaş, E. Fate and biodegradability potential of an emerging micropollutant diclofenac in subsurface environment. International Journal of Environmental Science and Technology 2018, 15, 1201. [CrossRef]

${ }^{8}$ da Silva, B. F.; Jelic, A.; López-Serna, R.; Mozeto, A. a.; Petrovic, M.; Barceló, D. Occurrence and distribution of pharmaceuticals in surface water, suspended solids and sediments of the Ebro river basin, Spain. Chemosphere 2011, 85, 1331. [CrossRef] [PubMed]

${ }^{9}$ Wick, J. Y. The History of Benzodiazepines. The Consultant Pharmacist 2013, 28, 538. [CrossRef]

${ }^{10}$ Nunes, C. N.; Pauluk, L. E.; dos Anjos, V. E.; Lopes, M. C.; Quináia, S. P. New approach to the determination of contaminants of emerging concern in natural water: study of alprazolam employing adsorptive cathodic stripping voltammetry. Analytical and Bioanalytical Chemistry2015, 407, 6171. [CrossRef]
${ }^{11}$ Brodin, T.; Fick, J.; Jonsson, M.; Klaminder, J. Dilute concentrations of a psychiatric drug alter behavior of fish from natural populations. Science 2013, 339, 814. [CrossRef] [PubMed]

12 Mendoza, A.; López de Alda, M.; GonzálezAlonso, S.; Mastroianni, N.; Barceló, D.; Valcárcel, Y. Occurrence of drugs of abuse and benzodiazepines in river waters from the Madrid Region (Central Spain). Chemosphere 2014, 95, 247. [CrossRef] [PubMed]

13 Racamonde, I.; Quintana, J. B.; Rodil, R.; Villaverde-de-Sáa, E.; Cela, R. Determination of benzodiazepines, related pharmaceuticals and metabolites in water by solid-phase extraction and liquid-chromatography-tandem mass spectrometry. Journal of Chromatography A 2014, 1352, 69. [CrossRef]

${ }^{14}$ Kosjek, T.; Perko, S.; Zupanc, M.; ZanoŠki Hren, M.; Landeka Dragičević, T.; Žigon, D.; Kompare, B.; Heath, E. Environmental occurrence, fate and transformation of benzodiazepines in water treatment. Water Research 2012, 46, 355. [CrossRef] ${ }^{15}$ Brodin, T.; Piovano, S.; Fick, J.; Klaminder, J.; Heynen, M.; Jonsson, M. Ecological effects of pharmaceuticals in aquatic systems--impacts through behavioural alterations. Philosophical Transactions of the Royal Society B: Biological Sciences 2014, 369, 1. [CrossRef]

${ }^{16}$ Overturf, C. L.; Overturf, M. D.; Huggett, D. B. Bioconcentration and endocrine disruption effects of diazepam in channel catfish, Ictalurus punctatus. Comparative Biochemistry and Physiology - Part C: Toxicology and Pharmacology 2016, 183-184, 46. [CrossRef]

17 Gebauer, D. L.; Pagnussat, N.; Piato, Â. L.; Schaefer, I. C.; Bonan, C. D.; Lara, D. R. Effects of anxiolytics in zebrafish: Similarities and differences between benzodiazepines, buspirone and ethanol. Pharmacology Biochemistry and Behavior2011, 99, 480. [CrossRef] [PubMed]

${ }_{18}$ Jindal, K.; Narayanam, M.; Singh, S. A systematic strategy for the identification and determination of pharmaceuticals in environment using advanced LC-MS tools: Application to ground water samples. Journal of Pharmaceutical and Biomedical Analysis 2015, 108, 86. [CrossRef] [PubMed]

19 Laugesen, S.; Roepstorff, P. Combination of two matrices results in improved performance of MALDI MS for peptide mass mapping and protein analysis. Journal of The American Society for Mass Spectrometry 2003, 14, 992. [CrossRef] [PubMed] 
${ }^{20} \mathrm{Gao}$, J.; Cassady, C. J. Negative ion production from peptides and proteins by matrix-assisted laser desorption/ionization time-of-flight mass spectrometry. Rapid Communications in Mass Spectrometry 2008, 22, 4066. [CrossRef]

21 Nozawa, H.; Minakata, K.; Yamagishi, I.; Hasegawa, K.; Wurita, A.; Gonmori, K.; Suzuki, O.; Watanabe, K. MALDI-TOF mass spectrometric determination of eight benzodiazepines with two of their metabolites in blood. Legal Medicine 2015, 17, 150. [CrossRef]

${ }^{22}$ Grant, D. C.; Helleur, R. J. Rapid screening of anthocyanins in berry samples by surfactantmediated matrix-assisted laser desorption/ ionization time-of-flight mass spectrometry. Rapid Communications in Mass Spectrometry 2008, 22, 156. [CrossRef]

${ }^{23}$ Ghobadi, M.; Yamini, Y.; Ebrahimpour, B. SPE coupled with dispersive liquid-liquid microextraction followed by GC with flame ionization detection for the determination of ultra-trace amounts of benzodiazepines. Journal of Separation Science 2014, 37, 287. [CrossRefl [PubMed]

24 Sivagnanam, K.; Komatsu, E.; Patrick, S.; Rampitsch, C.; Perreault, H.; Gräfenhan, T. Rapid screening of ergot alkaloids in sclerotia by maldi-tof mass spectrometry. Journal of AOAC Internationa/2016, 99, 895. [CrossRef]

${ }^{25}$ Komatsu, E.; Buist, M.; Roy, R.; Gomes de Oliveira, A. G.; Bodnar, E.; Salama, A.; Soulillou, J. P.; Perreault, $\mathrm{H}$. Characterization of immunoglobulins through analysis of $\mathrm{N}$-glycopeptides by MALDITOF MS. Methods 2016, 104, 170. [CrossRef] [PubMed]

${ }^{26}$ Yarbrough, M. L.; Lainhart, W.; Burnham, C. A. D. Identification of Nocardia, Streptomyces, and Tsukamurella using MALDI-TOF MS with the Bruker Biotyper. Diagnostic Microbiology and Infectious Disease 2017, 89, 92. [CrossRef]

27 Nozawa, H.; Minakata, K.; Yamagishi, I.; Hasegawa, K. Simultaneous determination of cyclic antidepressants and their related drugs and the estimation of new metabolites in human whole blood and urine by MALDI-QTOF-mass spectrometry. Forensic Toxicology 2016, 34, 244. [CrossRef]

${ }^{28}$ Petrie, B.; Barden, R.; Kasprzyk-Hordern, B. A review on emerging contaminants in wastewaters and the environment: Current knowledge, understudied areas and recommendations for future monitoring. Water Research 2014, 72, 3. [CrossRef] [PubMed]
${ }^{29}$ Calisto, V.; Domingues, M. R. M.; Esteves, V. I. Photodegradation of psychiatric pharmaceuticals in aquatic environments - Kinetics and photodegradation products. Water Research 2011, 45, 6097. [CrossRefl [PubMed]

${ }^{30}$ Wang, X.; Chen, J.; Yan, X.; Wang, X.; Zhang, J.; Huang, J.; Zhao, J. Heavy metal chemical extraction from industrial and municipal mixed sludge by ultrasound-assisted citric acid. Journal of Industrial and Engineering Chemistry 2015, 27, 368. [CrossRef]

${ }^{31}$ Climent, M. J.; Sánchez-Martín, M. J.; RodríguezCruz, M. S.; Pedreros, P.; Urrutia, R.; HerreroHernández, E. Determination of Pesticides in River Surface Waters of Central Chile Using SPE-GC-MS Multi-Residue Method. Journal of the Chilean Chemical Society 2018, 63, 4023. [CrossRef]

32 Stein, K.; Ramil, M.; Fink, G.; Sander, M.; Ternes, T. A. Analysis and sorption of psychoactive drugs onto sediment. Environmental Science \& Technology 2008, 42, 6415. [CrossRef] [PubMed] 33 Brett, J.; Murnion, B. Management of benzodiazepine misuse and dependence. Australian Prescriber 2015, 38, 152. [CrossRef]

${ }^{34}$ GoodPx Benzodiazepines. [Link]

35 Hadi, H.; Mouayed, M. Determination of Clonazepam in Pharmaceutical Preparations Using Simple High-Throughput Flow Injection System. Journal of Analytical Chemistry 2017, 72, 266. [CrossRef]

${ }^{36}$ Westland, J. L.; Dorman, F. L. QuEChERS extraction of benzodiazepines in biological matrices. Journal of Pharmaceutical Analysis 2013, 3, 509. [CrossRef] ${ }^{37}$ Ternes, T. A.; Bonerz, M.; Herrmann, N.; Löffler, D.; Keller, E.; Lacida, B. B.; Alder, A. C. Determination of pharmaceuticals, iodinated contrast media and musk fragrances in sludge by LC tandem MS and GC/MS. Journal of Chromatography A 2005, 1067, 213. [CrossRef].

${ }^{38}$ Rappsilber, J.; Mann, M.; Ishihama, Y. Protocol for micro-purification, enrichment, pre-fractionation and storage of peptides for proteomics using StageTips. Nature Protocols 2007, 2, 1896. [CrossRef].

${ }^{39}$ Guo, Z.; Zhang, Q.; Zou, H.; Guo, B.; Ni, J. A Method for the Analysis of Low-Mass Molecules by MALDI-TOF Mass Spectrometry. Analitycal Chemistry 2002, 74, 1637. [CrossRef]

${ }^{40}$ Pubchem Open Chemistry Database. [Link]

${ }^{41}$ Note, T.; Guidelines for the validation and verification of quantitative and qualitative test methods, NATA: Sidney, 2013. 
${ }^{42}$ Ternes, T.; Bonerz, M.; Schmidt, T. Determination of neutral pharmaceuticals in wastewater and rivers by liquid chromatography-electrospray tandem mass spectrometry. Journal of Chromatography A 2001, 938, 175. [CrossRef] [PubMed]

${ }_{43}$ Montagner, C. C.; Jardim, W. F. Spatial and seasonal variations of pharmaceuticals and endocrine disruptors in the Atibaia River, São Paulo State (Brazil). Journal of the Brazilian Chemical Society2011, 22, 1452. [CrossRef]

${ }^{44}$ Carmona, E.; Andreu, V.; Picó, Y. Occurrence of acidic pharmaceuticals and personal care products in Turia River Basin: From waste to drinking water. Science of the Total Environment2014, 484, 53. [CrossRef] [PubMed]

${ }^{45}$ Honeychurch, K. C.; Hart, J. P. Electrochemical detection of benzodiazepines, following liquid chromatography, for applications in pharmaceutical, biomedical and forensic investigations. Insciences Journal 2014, 4, 1. [CrossRef]

${ }^{46}$ Mart, J. Multi-residue method for the analysis of pharmaceutical compounds in sewage sludge , compost and sediments by sonication-assisted extraction and LC determination. Journal of Separation Science 2010, 33, 1760. [CrossRef] 